\title{
Dashboards in neonatology
}

This article was published in the following Dove Press journal:

Clinical Audit

8 July 2010

Number of times this article has been viewed

\author{
Christopher Flannigan' \\ Una Toland ${ }^{2}$ \\ Martina Hogan² \\ 'Royal Belfast Hospital for Sick \\ Children, ${ }^{2}$ Craigavon Area Hospital, \\ Neonatal Unit, Northern Ireland
}

Correspondence: Christopher Flannigan Royal Belfast Hospital for Sick Children, 180-I84 Falls Road, Belfast, BTI 2 6BE, Northern Ireland

Tel +4402890632484

Email: cflannigan@doctors.org.uk

\begin{abstract}
A clinical dashboard is defined as a toolset of visual displays developed to provide clinicians with the relevant and timely information they need to inform daily decisions that improve quality of patient care. The use of clinical dashboards in the National Hospital Service (NHS) is not a new concept, but it is one that has not been widely adopted throughout neonatology in the United Kingdom. The underuse of dashboards was also noted by the NHS Next Stage Review in 2008. It advocated for the development of dashboards in all clinical areas stating: "Our goal is that every provider of NHS services should systematically measure, analyze, and improve quality. They will need to develop their own quality frameworks, combining relevant indicators defined nationally, with those appropriate to local circumstances". In this article we outline the advantages to be gained by using dashboards to display information compared to using more traditional methods, using our own neonatal dashboard in Craigavon Hospital as an example.
\end{abstract}

Keywords: dashboards, neonatology

\section{Dashboards in neonatology}

The use of clinical dashboards in the National Hospital Service (NHS) is not a new concept, but it is one that has not been widely adopted throughout neonatology in the United Kingdom. Neonatology is a specialty where practicing evidence based medicine has always been important and over the past few years, like the rest of the NHS, there has been increasing emphasis on clinical effectiveness. If our aim in neonatology is to continue to provide the best standard of care to our patients, we cannot continue to overlook the valuable tool that is a clinical dashboard.

The underuse of dashboards in the United Kingdom was also noted by the NHS Next Stage Review in 2008. It advocated for the development of dashboards in all clinical areas stating, "Our goal is that every provider of NHS services should systematically measure, analyze, and improve quality. They will need to develop their own quality frameworks, combining relevant indicators defined nationally, with those appropriate to local circumstances". ${ }^{1}$ Despite this, published reports of their successful implementation into neonatal practice remain scarce. ${ }^{2}$

A clinical dashboard is defined as a toolset of visual displays developed to provide clinicians with the relevant and timely information they need to inform daily decisions that improve quality of patient care. ${ }^{3}$ There is no standard set of information that a clinical dashboard should display, but it should be developed in a way that allows an individual unit to monitor factors that are important to it; in neonatology this may include factors such as occupancy, environmental cleanliness, or uptake of mandatory staff training. 
The information provided by a clinical dashboard and the way that the information is used varies widely from department to department. Notwithstanding this, dashboards tend to have a number of features in common. As its name suggests, a dashboard displays its information using easy to interpret diagrams which have a high visual impact. The majority of clinical dashboards tend to use the same universally recognized color coding, based on the traffic light system. By using these colors it allows staff members to see at a glance how the unit is performing against its agreed targets, eg, areas in green where the unit is performing within its targets, areas in amber where the unit is falling slightly behind targets, and areas in red where there has been a major deviation from the agreed targets.

There are a number of advantages to be gained from using dashboards to display information compared to using more traditional methods. Firstly, using a dashboard to display data ensures that areas which are falling behind targets can quickly be identified and strategies put into place to

\% Staff recognized Neonatal course 2009 (BAPM recommendation $70 \%$ of staff should hold recognized course)
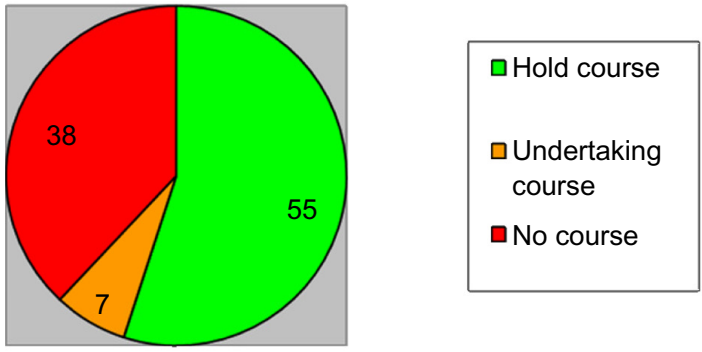

\section{$\%$ Average monthly score for hand hygiene in neonatal unit 2009 (expected compliance is 90\%)}

100

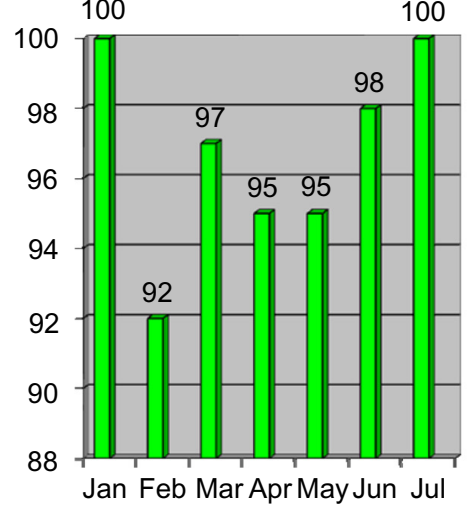

rectify the problems. The more traditional methods of data collection and analysis often result in delays before change can be implemented as time is lost in the data collection, interpretation, and presentation.

Secondly, the dashboard is an excellent communication tool for the modern NHS. With the implementation of the European Working Time Directive (EWTD) doctors are spending more time working shifts and less time in the unit during normal working hours. This means that it is becoming increasingly difficult to share new information with all the staff in the department at one time. The use of dashboards could possibly remedy this situation, whereby staff would be encouraged to regularly check it for updates on the performance of the unit. Night staff would particularly benefit from this as they are often unable to attend team meetings during normal working hours.

Thirdly, the dashboard provides a real time view of the unit's performance and by monitoring the trends in graph format, staff can obtain quicker feedback, address areas

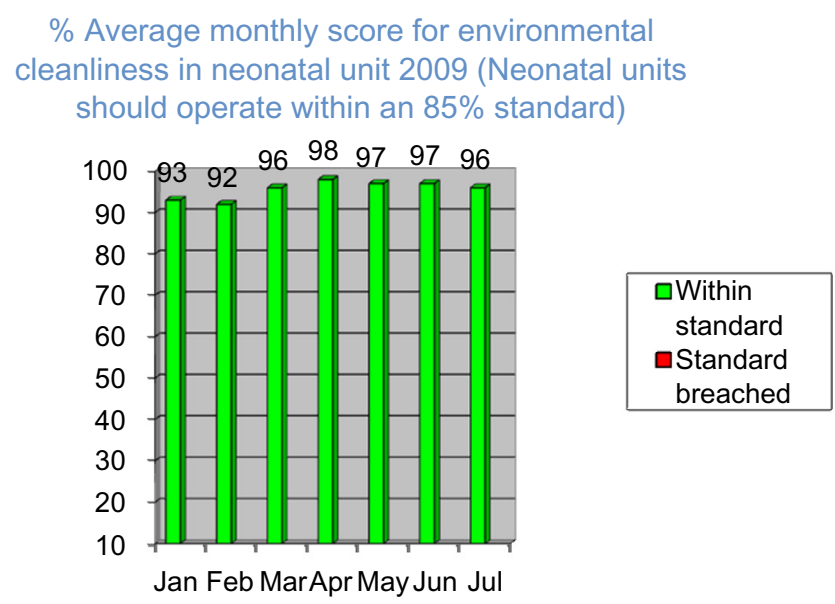

$\%$ Average monthly occupancy in neonatal unit 2008/09 (Neonatal units should operate within a $70 \%$ standard ref BAPM)

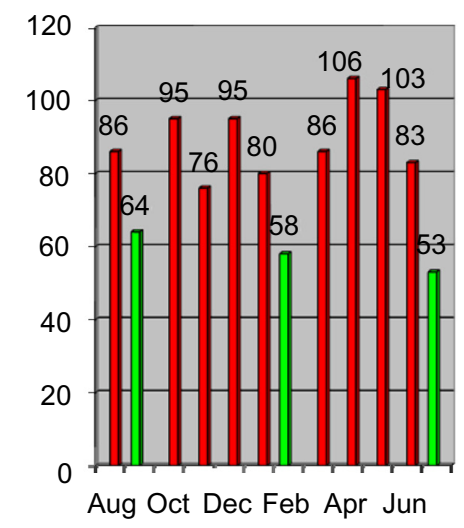

$\square$ Within standard

- Standard breached

Figure I A selection of graphs from our neonatal dashboard. 
of poor performance, and subsequently view the results of their efforts in a timely and visually pleasing form. As a direct consequence it would be hoped that staff satisfaction would improve and an increase in overall performance may therefore be more evident.

Finally, the best example to illustrate the advantages of a clinical dashboard in neonatology is from our own personal experience of working with them. In the neonatal unit in Craigavon Area Hospital there is a strong emphasis on clinical effectiveness. A dashboard has been in use for some time as a way of improving the quality of care delivered with a good success rate and excellent staff satisfaction. The dashboard is used to record our performance against local, regional, and national standards.

The data recorded on the dashboard has played a major role in introducing change within the neonatal unit. The best example of this was data supplied on occupancy and activity levels being used to form a business case to successfully employ an additional 10 neonatal nurses. In this particular instance the use of the dashboard quickly identified problems, induced change, and subsequently provided a better standard of patient care.

We also display data showing results of ongoing audits and environmental cleanliness score. Using the dashboard has proved particularly useful in keeping a record of the uptake of mandatory staff training. Data displayed on the dashboard act as informal reminders to staff who still need to complete their training.

A clinical dashboard has been successfully implemented into our neonatal unit and has been found to be a useful tool both for monitoring performance and inducing change. Dashboards seem to be one of the hot topics in the NHS at present and with their development having been recommended by both The NHS Next Stage Review and The Health Informatics Review it is likely that a clinical dashboard will be found in numerous neonatal units in the foreseeable future.

\section{Disclosure}

The authors report no conflicts of interest in this work.

\section{References}

1. High Quality Care for All. NHS next stage review final report. Department of Health. Crown Copyright 2008. Available at: http://www.dh.gov. uk/prod_consum_dh/groups/dh_digitalassets/@dh/@en/documents/ digitalasset/dh_085828.pdf

2. Spitzer AR. The Electronic Medical Record and the Data Warehouse in Neonatal Practice - Improving Patient Care Through Modern Technology. Neonatology Today. 2007;2(9):1-8. Available at: http://www. neonatologytoday.net/newsletters/nt-sep07.pdf

3. Clinical Dashboards. NHS connecting for health 2008. Available at: http://www.connectingforhealth.nhs.uk/systemsandservices/clindash
Clinical Audit

\section{Publish your work in this journal}

Clinical Audit is an international, peer-reviewed, open access journal focusing on the processes and outcomes of clinical audit in any area of healthcare. All aspects of patient care are addressed within the journal and practitioners from all disciplines are invited to submit their work. Areas covered include: Publication of audits; How an audit has changed practice;

\section{Dovepress}

Practical tips on how to do audits and to avoid pitfalls; How audits have changed patient care; Calls and justifications for new audits. The manuscript management system is completely online and includes a very quick and fair peer-review system, which is all easy to use. Visit http://www.dovepress. com/testimonials.php to read real quotes from published authors. 